\title{
Proceeding
}

Supplementary Issue: Summer Conferences of Sports Science. Costa Blanca Sports Science Events, 25-26 September 2020. Alicante, Spain.

\section{Achilles tendon pathologies: How to choose the best treatment}

\author{
DOMIZIANO TARANTINO, STEFANO PALERMI, FELICE SIRICO, GIOVANNI BALATO, ALESSIO \\ D'ADDONA, BRUNO CORRADO \\ Department of Public Health, University Federico II of Naples, Naples, Italy
}

\begin{abstract}
The Achilles tendon is the thickest and strongest tendon of the human body and it gets frequently injured during sports activity. The incidence of Achilles tendon pathologies has increased over the last decades, especially in the last few years, as a result of the increased sports participation among general population and for the diffusion of competitive sports at a high level. Although the increased interest and number of studies about Achilles tendon pathologies, at the moment there is not a consensual point of view on which is the best treatment for Achilles tendon injuries, and its management is still controversial. Treatment options mainly include conservative treatment and surgical repair. The decision for treatment in patients with an Achilles tendon pathology should be tailored on patient's needs and level of activity, since patients with high activity levels may accept the risk of a higher complication rate to rapidly return to previous activity, while less active patients or those who cannot undergo surgery due to comorbidities may choose the non-operative option to decrease the risk of infection and other complications. The aim of this article is to give an insight about the most used and recent treatment options for Achilles tendon pathologies.
\end{abstract}

Keywords: Achilles tendon; Tendinopathy; Tendon injuries; Therapeutics.

\section{Cite this article as:}

Tarantino, D., Palermi, S., Sirico, F., Balato, G., D‘Addona, A., \& Corrado, B. (2020). Achilles tendon pathologies: How to choose the best treatment. Journal of Human Sport and Exercise, 15(4proc), S1300-S1321. doi:https://doi.org/10.14198/jhse.2020.15.Proc4.29

Corresponding author. Department of Public Health, University Federico Il of Naples, Naples, Italy. https://orcid.org/0000-00030990-3428

E-mail: bruno.corrado@unina.it

Abstract submitted to: Spring Conferences of Sports Science. Costa Blanca Sports Science Events, 19-20 June 2020. Alicante, Spain.

JOURNAL OF HUMAN SPORT \& EXERCISE ISSN 1988-5202

(c) Faculty of Education. University of Alicante

doi:10.14198/jhse.2020.15.Proc4.29

S1300 $2020 \mid$ Proc4 | VOLUME 15

(C) 2020 University of Alicante 


\section{INTRODUCTION}

The Achilles tendon is the thickest, strongest and largest tendon in the human body, and it can undergo both degenerative and traumatic processes (Aicale et al., 2018; Maffulli et al., 2018).

Tendinopathies are one of the most frequent orthopaedic injuries (Loiacono et al., 2019), and the Achilles tendon is the most commonly injured tendon in the human body, accounting for $20 \%$ of all tendon ruptures (Oda et al., 2017). Ruptures of the Achilles tendon occur mainly during sports activities, more frequently in middle-aged men, especially untrained and recreational athletes who play sports occasionally (Wertz et al., 2013), even though ruptures can occur in younger people.

The incidence of Achilles tendon ruptures has increased over the last several decades, probably as a result of widespread sports participation (Lantto et al., 2015; Maffulli et al., 1999).

Patients with an Achilles tendon rupture report sudden and severe pain in the acute phase, and, if left untreated, the injury result in worsened physical function (Bertelli et al., 2009).

Achilles tendon tears necessitate a prolonged recovery, leaving a $10 \%$ to $30 \%$ reduction in functional calf strength (Heikkinen et al., 2016; Olsson et al., 2011; Olsson et al., 2013; Silbernagel et al., 2012; Willits et al., 2010) and endurance (Bostick et al., 2010) despite increased muscle activity (Horstmann et al., 2012; Suydam et al., 2015). The injury produces long-term limitations (Heikkinen et al., 2016; Horstmann et al., 2012; Lantto et al., 2015; Mavrodontidis et al., 2015), and many patients fail to return to sports activities at the same level of performance as before injury (Zellers et al., 2016).

Achilles tendinopathy is clinically characterized by pain and swelling, in and around the tendon, mainly arising from overuse, but often presenting in middle-aged overweight patients with no history of increased physical activity (Maffulli et al., 1998; Sirico et al., 2020; Tarantino and Brancaccio, 2019). It can be categorized as insertional and non-insertional, two distinct disorders with different underlying pathophysiology and management options (Longo et al., 2008). Achilles tendinopathy is a common cause of disability in many athletes because of continuous prolonged intense functional demands imposed on the Achilles tendon, with pain being the main symptom of this pathology, it may occur during the entire exercise session, and it may interfere with activities of daily living (Corrado et al., 2019; Corrado et al., 2020; Corrado et al., 2020; Maffulli et al., 2015).

The diagnosis relies on clinical examination, and imaging techniques can be useful in providing additional clinical information (Maffulli et al., 2020).

After rupture, tendons heal forming scar tissue, and most will never regain the same collagen structure, composition, and organization of healthy tissue (Aicale et al., 2017; Bisaccia et al., 2019). This can lead to a decrease in the mechanical properties of the tissue and increased potential for re-rupture (Lin et al., 2004).

There is no consensus on which is the best treatment for Achilles tendon ruptures, and its management is still controversial. The management of Achilles tendinopathy lacks evidence-based support, and people who suffer from Achilles tendinopathy are at risk of long-term morbidity with unpredictable clinical outcome (Kader et al., 2002). 
Treatment options for Achilles tendon rupture include conservative treatment (plaster casting or bracing) and surgical (open or percutaneous) repair (Carmont et al., 2011), while for Achilles tendinopathy treatment options are conservative (such as nonsteroidal anti-inflammatory drugs, eccentric exercises, low-energy shockwave therapy, etc.) treatment (Corrado et al., 2019; Maffulli et al., 2020) and surgical (open or minimally invasive) repair (Aicale et al., 2018). Growing evidences support the use of biological therapies for tendinopathies treatment (Di Meglio et al., 2020).

\section{ACHILLES TENDON RUPTURE}

\section{Management of Achilles tendon rupture: operative or non-operative?}

The management of patients who suffer an Achilles tendon rupture can be broadly divided in 2 groups: operative and non-operative, with the final decision about the treatment usually taken according to the preference of both the surgeon and the patients. The choice of the type of management should take into account the age, occupation, and level of sporting activity of each patient (Longo et al., 2013).

Surgical management consists of open or percutaneous repair, whereas conservative management consists of immobilization or functional bracing (Longo et al., 2013). Recently, more evidence has become available for the use of percutaneous techniques than for open surgery (Khan et al., 2005; Longo et al., 2008), and for the use of early mobilization (Maffulli et al., 2003; Maffulli et al., 2003; Maffulli, 2006). In the last 2 decades, surgical treatment has been the method of choice, especially in athletes and young people and in cases of delayed ruptures, whereas conservative, non-operative management can be used in non-athletes (Farizon et al., 1997).

The goals of the management of Achilles tendon rupture are to minimize the morbidity of the injury, reduce tendon lengthening, optimize rapid return to full function, and minimize other complications (Gross and Nunley, 2016; Longo et al., 2013; Olsson et al., 2013).

Recent systematic reviews have shown that open operative management of acute Achilles tendon ruptures significantly reduces the risk of re-rupture compared with non-operative treatment, but is associated with post-operative wound complications because of the fragility and limited vascularization of the skin (Knobe et al., 2015), and also with an increased risk of infection and morbidity (Saxena et al., 2008).

Deng et al. (Deng et al., 2017) compared the outcomes of surgical treatment versus conservative management for acute Achilles tendon rupture, and pointed out that the total re-rupture rate was significantly lower in surgical group than that in the non-surgical group, but no significant differences were found between the 2 treatment groups in the incidence of deep venous thrombosis, the number who returned to sport, ankle range of motion (dorsiflexion, plantarflexion), Achilles tendon total rupture score, or physical activity scale.

A meta-analysis (van der Eng et al., 2013) showed no significant differences in the rate of re-rupture in surgically treated patients and conservatively treated patients after early weightbearing. An analysis of patients with delayed weightbearing after 4 or more weeks also did not demonstrate a difference in the rerupture rate. Finally, no differences were seen in the incidence of minor or major complications after early weightbearing in surgically and conservatively treated patients.

Another recent study showed that re-rupture rates in both surgical and non-surgical treatments were low (2.3\% and $3.9 \%$, respectively), the rate of postoperative complication after surgery was equally low (4.9\%), and the differences between surgical and non-operative management were small for both outcomes (Ochen 
et al., 2019). So, even if the differences may have been statistically significant, the clinical relevance was at least questionable (Maffulli and Peretti, 2019).

Manent et al. (Manent et al., 2019) reported no case of total re-rupture and similar efficacy for conservative, percutaneous, and open surgery treatments for acute Achilles tendon rupture at 1-year follow-up with an early weightbearing rehabilitation programme.

Given the above results, what we can state is that even if operative and non-operative treatments have both their pro and cons, there is no general consensus about their efficacy and reliability.

Recent research has focused on how the biomechanical properties of the healing tendon relate to functional performance after treatment, using different treatment methods with the aim of reducing tendon elongation and optimizing stiffness (Schepull et al., 2012; Silbernagel et al., 2010; Silbernagel et al., 2012). In cadaveric studies, Costa et al. (Costa et al., 2006) determined that $1 \mathrm{~cm}$ of tenotomised tendon-end separation produced a $12^{\circ}$ increase in ankle dorsiflexion. With non-operative management consisting of cast immobilization and early weightbearing, the resting flexion angle has been shown to correlate with muscle strength (Ecker et al., 2016). Minimally invasive repair, using an absorbable suture, and accelerated rehabilitation have been shown to lead to $5^{\circ}$ increased dorsiflexion at rest, indicating less tension and/or increased elongation of the muscle-tendon unit.

A recent study by Okoroha et al. (Okoroha et al., 2020) pointed out that no difference was found in tendon lengthening between patients undergoing traditional versus accelerated rehabilitation postoperatively after operative repair of Achilles tendon ruptures. The greatest amount of lengthening was found to occur between 2 and 6 weeks postoperatively, and tendon lengthening decreased significantly after 6 weeks.

\section{Conservative management of Achilles tendon rupture}

Conservative treatment consists of immobilization in a below-knee plaster cast in gravity equinus for 4 weeks, followed by a more neutral position for a further 4 weeks: this method is considered the most common nonoperative protocol of management of Achilles tendon rupture (Edna, 1980; Gillies and Chalmers, 1970; Jacobs et al., 1978; Lea and Smith, 1972; Lildholdt and Munch-Jorgensen, 1976; Persson and Wredmark, 1979).

Other proposed protocols are to maintain of the gravity equinus position for 2 weeks, followed by a more neutral position for a further 2 weeks. After this period, a below-knee plaster cast with the foot plantigrade is applied for a further 2 weeks, allowing weightbearing for the last 2 weeks of this management regime. After 1 to 3 weeks of immobilization, braces, splints, or shoes with limitation of dorsiflexion and increased heel height have been used for functional rehabilitation (Eames et al., 1997; McComis et al., 1997; Saleh et al., 1992; Thermann et al., 2000).

Following immobilization, the soleus muscle is particularly susceptible to atrophy (Vrbova, 1963). The calf circumference greatly decreases after non-operative management compared with operative management (Häggmark et al., 1986; Heikkinen et al., 2017). The reports on early functional treatment suggest good functional outcome and low re-rupture rates (Wong et al., 2002).

Korkmaz et al. (Korkmaz et al., 2015) recruited patients treated with partial weightbearing beginning the same day of conservative treatment, and other patients treated with non-weightbearing after a 4-week period. Wellconducted early weightbearing treatment regimen for Achilles tendon rupture provides good clinical 
outcomes, with a complication rate no higher than after delayed mobilization. Early weightbearing, since it provides advantages such as comfortable healing, reduces lost work time, and allows earlier reintegration into the community.

Conservative management does not present any wound complications and damage to the sural nerve: the high risk of re-rupture (Khan et al., 2004; Möller et al., 2001) of some years ago has generally decreased with the more modern early weightbearing and mobilization techniques (Maffulli and Peretti, 2020).

In 2008, Metz et al. (Metz et al., 2008) pointed out that minimally invasive surgical treatment of acute Achilles tendon rupture appears to have a lower risk of complications than non-operative treatment using functional bracing.

One year later, the same group (Metz et al., 2009) found that, if such complications are avoided, conservative treatment of acute Achilles tendon ruptures by functional bracing is as effective in the recovery of calf muscle strength as minimally invasive surgical repair.

Soroceanu et al. (Soroceanu et al., 2012) suggested that surgical treatment and non-surgical treatment of acute Achilles tendon rupture were equivalent with regard to re-rupture rate when the non-surgical treatment protocol included early range of motion; for this reason, conservative treatment should be considered at centres using functional rehabilitation. Surgical repair should be preferred at centres that do not employ earlyrange-of-motion protocols as it decreased the re-rupture risk in such patients by $8.8 \%$, with the number of patients needed to treat to prevent one re-rupture being 12 .

Costa et al. (Costa et al., 2020) measured the Achilles Tendon Rupture Score, quality of life, complications and resource use of patients receiving non-operative treatment for an Achilles tendon rupture treated with plaster cast compared with those treated with functional bracing. They found that early weightbearing in a functional brace provides similar outcomes to traditional plaster casting and is safe for patients receiving nonoperative treatment of Achilles tendon rupture.

Ecker et al. (Ecker et al., 2016) evaluated the use of a standardized non-operative early weightbearing protocol for Achilles tendon rupture consisting in a combination of an equinus cast and rehabilitation boot, which promoted immediate full weightbearing and early functional rehabilitation. They found that their protocol resulted in good functional outcome and patient satisfaction despite observing the common tendon elongation and loss of muscle strength in some patients, with only the $5 \%$ of their patients undergone operative treatment due to probably insufficient early tendon healing as seen at 10 to 14 days after the injury. Six weeks of walking-cast in equinus and 6 further weeks of protected walking in the boot gave acceptable protection against re-rupture and excessive tendon lengthening.

\section{Open surgery for Achilles tendon rupture}

Open surgical repair has classically been considered the gold standard for the management of Achilles tendon ruptures in young, fit individuals (Longo et al., 2013). Moreover, the numerous advances in surgical techniques, such as in postoperative rehabilitation protocols, have encouraged many surgeons to favour direct tendon repair (Myerson, 1999). In addition, the excellent results of surgical repair concerning re-rupture rates and calf muscle strength may help many athletes to return to preinjury physical activities (Longo et al., 2013). 
There are several open surgical procedures, ranging from a simple end-to-end suturing by Bunnell or Kessler sutures, to more complex repairs using fascial reinforcement or tendon grafts (Soma and Mandelbaum, 1995).

Open end-to-end repair can be carried out under local, regional, or general anaesthesia. The procedure is performed with the patient prone, with the feet over a pillow or outside the operating table. Excessive plantar flexion increases the risk of overtightening the repair and shortening of the tendon (Karlsson et al., 2017). The risk of lengthening is a more common issue and should be avoided (Aicale et al., 2017). Tendon lengthening will lead to reduced plantar flexion strength (Silbernagel et al., 2012). A 5-8 cm posteromedial skin incision is preferred to minimize any risk of injury to the branches of the sural nerve.

Several types of tendon grafts and techniques can be performed to repair an Achilles tendon defect: open reconstruction with gastrocnemius V-Y advancement (Hsu et al., 2017), free/turndown gastrocnemius flap augmentation (Nilsson-Helander et al., 2017), or free hamstring open augmentation for delayed Achilles tendon rupture (Carmont et al., 2017). However, primary augmentation has been shown to produce more complications and no junctional advantages over simple end-to-end repair.

Patients who undergo open operative repair are more often are serious athletes who comply well with postoperative management (Longo et al., 2013).

\section{Percutaneous techniques for Achilles tendon rupture}

Percutaneous techniques, comparable for clinical effectiveness to traditional open procedures (Goren et al., 2005), are advocated for their lower complication rates, and provide encouraging results in older individuals, diabetic patients, and high performance athletes (Khan et al., 2005; Maffulli et al., 2010; Maffulli et al., 2011; Maffulli et al., 2011).

The first percutaneous technique was described by Ma \& Griffith in 1977: they developed a method for percutaneous repair as a compromise between the open surgical and non-surgical managements ( $M a$ and Griffith, 1977). This technique developed a reputation for iatrogenic sural nerve injuries, although is still commonly used. The Ma \& Griffith repair consists of a Bunnel suture applied to the proximal tendon and a box suture distally in the stump inserted through 6 para-tendinous stab incisions.

In 1999, Webb and Bannister developed a percutaneous technique, using 3 midline transverse $2.5-\mathrm{cm}$ incisions over the posterior aspect of the Achilles tendon, rather than performing at the side close to the nerve, which minimized injury to the sural nerve and breakdown of the wound, while maintaining the rerupture rate of the tendon similar with that achieved by open repair (Webb and Bannister, 1999).

McClelland and Maffulli (McClelland and Maffulli, 2002) later modified this method using stronger absorbable sutures and a Kessler suture configuration.

The Carmont and Maffulli's technique (Carmont and Maffulli, 2008) is cheap, and allows a strong repair, as it enables the use of a greater number of suture strands (eight) for the repair of the Achilles tendon. This technique provided favourable outcome for patients older than 65 and for elite athletes, producing similar outcomes when compared to percutaneous repair in younger patients (Maffulli et al., 2010; Maffulli et al., 2011). This percutaneous technique reduces the risk for sural nerve damage, a troublesome complication in up to $60 \%$ of patients following percutaneous repair, and impairing functional outcome (Maes et al., 2006; Majewski et al., 2006). Making longitudinal stab skin incisions parallel to the course of the nerve, as close to 
the lateral tendon edge as possible, prevents sural nerve injury (Ma and Griffith, 1977; Majewski et al., 2006). This procedure also allows the torn ends of the tendon to be advanced distally symmetrically, simultaneously pulling the medial and lateral end of the suture, approximating the torn ends until the defect is no longer palpable, maintaining the foot in plantar flexion (Maffulli et al., 2017).

Guillo et al. (Guillo et al., 2013) presented the clinical and functional outcomes of active patients undergoing percutaneous repair (using Carmont and Maffulli's technique) after acute subcutaneous ruptures of the Achilles tendon. This percutaneous technique for repair of the ruptures of the Achilles tendon, associated with immediate protected weightbearing and early active mobilization, provides encouraging outcome in terms of strength and return to pre-operative level of sport activity.

Al-Mouazzen et al. (Al-Mouazzen et al., 2015) found out that percutaneous repair of the Achilles tendon followed by early weightbearing and accelerated rehabilitation achieves good functional outcome.

\section{ACHILLES TENDINOPATHY}

\section{Management of Achilles tendinopathy: operative or non-operative?}

The first line of management for Achilles tendinopathy is conservative, and different treatments such as nonsteroidal anti-inflammatory drugs, (NSAIDs) physical therapy, taping, cryotherapy, shock wave therapy, hyperthermia and various peritendinous injections have been used with varying success (Aicale et al., 2018; Aicale et al., 2019; Corrado et al., 2019; Maffulli et al., 2017).

In $24 \%$ to $45.5 \%$ of patients with Achilles tendinopathy, conservative management is unsuccessful, and surgery is recommended after exhausting conservative management, often tried for at least 6 months, since Achilles tendinopathy may resolve during this period in up to three quarters of patients (Aicale et al., 2018; Maffulli et al., 2020; Maffulli and Kader, 2002; Silbernagel et al., 2011).

However, long-standing Achilles tendinopathy is associated with poor postoperative results, with a greater rate of reoperation before reaching an acceptable outcome (Maffulli et al., 1999).

Surgery is successful in up to $85 \%$ of patients (Maffulli and Kader, 2002).

Open surgery for tendinopathy of the main body of the Achilles tendon can be considered if prolonged conservative management fails (Aicale et al., 2018).

The main concern with open surgery is the risk of complications (Aicale et al., 2019). A study on 432 patients reported an overall complication rate of $11 \%$ (Paavola et al., 2000). These may include skin edge necrosis, wound infection, seroma formation, haematoma, fibrotic reactions or excessive scar formation, sural nerve irritation or injury, tendon rupture and thromboembolic disease.

For all the above reasons, patients should be informed of the potential failure of the procedure, risks of wound complications and at times prolonged recovery time (Saxena et al., 2008).

The rate of these complications might decrease with the use of minimally invasive techniques (Maffulli et al., 2017). 
Minimally invasive techniques reduce the risks of infection, are technically easy to master, and are inexpensive (Aicale et al., 2018). Different minimally invasive procedures can be also used together to optimize the outcomes (Longo et al., 2009).

A systematic review reported that the average success rate of minimally invasive techniques and open procedures is, respectively, $83.6 \%$ and 78.9 , while the complication rate is, respectively, $5.3 \%$ and $10.5 \%$ (Lohrer et al., 2016). The success rates of minimally invasive and open treatments are similar, but there is a tendency for more complications to occur in open procedures. Therefore, minimally invasive surgical treatment would appear to be a useful intermediate step between failed conservative treatment and formal open surgery (Aicale et al., 2018; Maffulli et al., 2017).

\section{Conservative management of Achilles tendinopathy}

Several conservative therapeutic options are available, but most of them lack hard scientific background (Maffulli and Longo, 2008).

NSAIDs are commonly used for the management of Achilles tendinopathy, even though data showed a modest effect on acute symptoms in the short term (Glaser et al., 2008). The analgesic effect of NSAIDs allows patients to ignore early symptoms, with the risk of further damage to the affected tendon and delaying definitive healing.

NSAIDs can be useful for pain control to allow effective eccentric strengthening (another therapeutic option further described) as well as gastrocnemius and soleus stretching. Potential harms of NSAIDS (such as ulcers, hypertension, etc) need to be weighted up for each patient, balancing potential risks and benefits (Maffulli et al., 2020).

Cryotherapy is also widely used for analgesia, to reduce the metabolic rate of the tendon, and to decrease the extravasation of blood and protein from new capillaries found in tendon injuries (Kannus and Józsa, 1991). Anyway, there is no evidence that this is an effective treatment for Achilles tendinopathy (Maffulli et al., 2020).

Eccentric exercises have been proposed to promote collagen fibres cross-link formation within the tendon, thereby facilitating tendon remodelling (Maffulli and Longo, 2008).

Eccentric exercises are the most effective conservative treatment for non-insertional Achilles tendinopathy (Aicale et al., 2019), with good results reported (Maffulli et al., 2015; Weinreb et al., 2014), and with the Alfredson's protocol being the most commonly used protocol: the exercises are performed in three sets of 15 repetitions, twice a day for 12 weeks (Alfredson et al., 1998).

The results of a meta-analysis, which outlined the best pooled data supporting eccentric exercises, reported that the majority of the studies adopted the Alfredson's protocol (Sussmilch-Leitch et al., 2012). Alfredson and other Scandinavian authors have reported excellent results in prospective randomized control trials (Mafi et al., 2001; Roos et al., 2004; Silbernagel et al., 2001).

The results of eccentric training from other study groups are less convincing, with a 50-60\% of good outcome after a regime of eccentric training both in athletic and sedentary patients (Sayana and Maffulli, 2007) or even lower (Rompe et al., 2007; Sayana and Maffulli, 2007); this can result from many factors, and the protocol requires motivated and compliant patients. 
Eccentric exercises alone may not work in all patients (Sayana and Maffulli, 2007), and their the mechanism of action is not completely understood (Maffulli et al., 2015).

In general, the overall trend suggests a positive effect of eccentric exercises, with no reported adverse effects (Maffulli and Longo, 2008). Combining eccentric training and shock wave therapy produces higher success rates compared to eccentric loading alone or shock wave therapy alone (Rompe et al., 2009).

Other protocols, such as eccentric-concentric progressing to eccentric (i.e. Silbernagel combined) (Silbernagel et al., 2001) and eccentric-concentric (i.e. Stanish and Curwin) (Stanish et al., 1986), have been described (Aicale et al., 2019). A systematic review showed that combined type exercises have equivalent results to the traditional Alfredson's protocol (Malliaras et al., 2013). Isotonic, isokinetic and concentric loading have also been described, but are inferior to the eccentric-type exercises (Mafi et al., 2001; NiesenVertommen et al., 1992).

Where available, extracorporeal shockwave therapy (ESWT) should probably be a second-line treatment (Aicale et al., 2018; Aicale et al., 2019; Corrado et al. 2019). ESWT works on two aspects of the clinical response, that are tissue healing and pain transmission (Aicale et al., 2019).

The combined use of low-energy shock wave therapy and eccentric exercises is beneficial (Kane et al., 2008). However, when low energy shock wave therapy is not used following the recommendations and modalities outlined in the available trials, the results can be disappointing (Costa et al., 2005).

Orthotics are widely used in conservative management, with heel pads being the most commonly prescribed (Maffulli et al., 2020). There is little evidence to support their use (Lowdon et al., 1984). No differences between management with the AirHeel brace and an eccentric training programme were found in patients with chronic Achilles tendon pain (Petersen et al., 2007). The combination of eccentric training with the AirHeel Brace does not produce a synergistic effect (de Jonge et al., 2010; Knobloch et al., 2008; Knobloch et al., 2008; Petersen et al., 2007).

The efficacy of nitric oxide administration via an adhesive patch in patients with tendinopathy of the main body of the Achilles was evaluated by Paoloni et al. (Paoloni et al., 2004). Topical glyceryltrinitrate was effective in chronic noninsertional Achilles tendinopathy, with treatment benefits continuing for 3 years (Paoloni and Murrell, 2007). However, a more recent study questioned the clinical benefit of topical glyceryltrinitrate patches (Kane et al., 2008).

Hyperthermia can be another option for the management of patients with Achilles tendinopathy, with some studies confirming these potential advantages (Giombini et al., 2002).

Ultrasound therapy is widely available and frequently used (Maffulli et al., 2020). However, some studies have repeatedly concluded that there is insufficient evidence to support a beneficial effect of ultrasound therapy at the current clinical dosages (Warden, 2003). A randomized controlled trial by Chester et al. showed similar outcome between heavy eccentric loading and ultrasound for the management of Achilles tendinopathy in subjects with a relatively sedentary lifestyle, with no adverse effects (Chester et al., 2008).

Various injections therapies have been used for Achilles tendinopathies (Maffulli et al., 2020; van Sterkenburg and van Dijk, 2011). At present, studies which demonstrate the superiority of one injection technique or of one substance over another are few (Maffulli et al., 2020). 
The use of PRP seems to be growing exponentially, especially among sports medicine physicians, but the only well-designed RCT published on PRP in Achilles tendinopathy showed no significant difference in pain or activity level between PRP and saline injection at 6,12 or 24 weeks when combined with an eccentric stretching programme (de Vos et al., 2010).

High volume image guided injections significantly reduce pain and improve function in patients with resistant Achilles tendinopathy (Chan et al., 2008) and seem to be more effective in improving outcomes of chronic Achilles tendinopathy than PRP in the short term (Boesen et al., 2017).

\section{Open surgery for Achilles tendinopathy}

Successful results have been reported with open surgery, which is relatively straightforward, showing varying success rates between 50\% and 100\% (Kvist and Kvist, 1980; Lohrer et al., 2016; Schepsis and Leach, 1987; Snook, 1972) with removal of intra-tendinous lesions and more than $50 \%$ of tendon debrided, and latepresenting lesions showing significantly fewer good to excellent results (Maffulli et al., 1999; Maffulli et al., 2020; Paavola et al., 2000). For non-insertional Achilles tendinopathy, surgery has traditionally involved a large incision and excision of all of the pathological tissue. Occasionally, it may require concomitant transfer of a local tendon to reinforce the weakened Achilles tendon (Longo et al., 2009). The peroneus brevis, the ipsilateral free semitendinosus, and the flexor hallux longus tendons can be used as tendon grafts (Aicale et al., 2017; Aicale et al., 2017; Maffulli et al., 2017).

\section{Minimally invasive techniques for Achilles tendinopathy}

Minimally invasive therapies which strip the paratenon from the tendon, either directly (Longo et al., 2008) or indirectly with high-volume fluid injection (Chan et al., 2008), have shown good initial results in relieving the symptoms of non-insertional Achilles tendinopathy (Alfredson, 2011; Maffulli et al., 2017).

Multiple percutaneous longitudinal tenotomies, which can be performed under ultrasound guidance, produce good results, with the further advantage of being able to perform the procedure under local anaesthesia in an outpatient setting (Maffulli et al., 1997; Testa et al., 2002). Minimally invasive open debridement with resection of the plantaris tendon has also shown promising results with minimal complications in elite athletes and regular patients with non-insertional Achilles tendinopathy (Alfredson, 2011; Calder et al., 2015; Masci et al., 2015; Pearce et al., 2012; van Sterkenburg et al., 2011).

The endoscopic procedures are useful to minimize the soft tissue dissection and to supplement junction without restoring anatomical continuity (Aicale et al., 2017; Aicale et al., 2017; Aicale et al., 2019; Maffulli et al., 2017; Maffulli et al., 2020).

These techniques may be securely performed, are minimally invasive, have low morbidity, and allow most patients to return to pre-injury sporting and daily activities (Maffulli et al., 2017).

There are no comparative studies between the different minimally invasive approaches, and therefore it is unclear whether it is necessary to perform longitudinal tenotomies or to excise the plantaris tendon (Aicale et al., 2019).

Therefore, minimally invasive surgical treatment would appear to be a useful intermediate step between failed conservative treatment and formal open surgery (Maffulli et al., 2017). 


\section{CONCLUSIONS FOR ACHILLES TENDON RUPTURE}

There is no consensus regarding the best treatment of Achilles tendon pathologies, and the literature on the different available treatment options is far from being universally accepted.

In a recent retrospective study, Maffulli et al. (Maffulli et al., 2017) found out that clinical and functional outcomes following surgical repair, percutaneous and open, of the Achilles tendon are significantly improved than following conservative management. They pointed out that percutaneous repair is a good compromise, allowing accurate re-approximation of the tendon ends, and avoiding wound healing complications (Ma and Griffith, 1977).

Karabinas et al. (Karabinas et al., 2014) compared the post-operative clinical and functional results of percutaneous versus open repair of acute Achilles tendon ruptures: clinical and functional results after both open and percutaneous repair of acute Achilles tendon ruptures are similar, but cosmetic appearance is superior in patients who had a percutaneous treatment.

Minimally invasive surgery can produce similar results to those obtained with open surgery, providing decreased peri-operative morbidity, decreased duration of hospital stay, and reduced costs (d'Addona et al., 2020). Multicentre studies with longer follow-up are needed to justify the long-term advantages of these techniques over traditional ones (Maffulli et al., 2010).

Treatment should attempt optimal restoration of tendon length, tension, and stiffness.

Some patients may prefer non-operative treatment with a higher rate of re-rupture and an increased risk of tendon elongation, while other patients may prefer to undergo surgery that may offer superior functional outcomes, at the risk of an increased rate of wound complications.

Although there is no clear consensus regarding the optimal postoperative rehabilitation protocol for this injury, most physicians advocate early range of motion exercises and weightbearing. In the future, tissue engineering may lead to improved management of these injuries (Maquirriain, 2011).

\section{CONCLUSION FOR ACHILLES TENDINOPATHY}

The management of tendinopathy remains a major challenge. Advances in operative management are being made and are underpinned by a greater understanding of the pathologic changes of the overuse tendon injury within sport (Aicale et al., 2018).

The natural history and clinical course of Achilles tendinopathy are unclear, and the condition may be selflimiting in many patients. The lesion is a failed healing response of the tendon, with differences dependent on the site of the lesion (Aicale et al., 2018). Therefore, it is important to establish whether the many commonly used treatments, including surgery, really work (Maffulli et al., 2020).

It would be reasonable to refer the patient to a physical therapist to start a programme of eccentric exercises. If the condition does not respond to these interventions, shock wave therapy, or nitric oxide patches might be considered, although data on their efficacy are limited (Maffulli et al., 2020). The high recurrence rate for Achilles tendinopathy when managed conservatively reflects the chronic and recurrent character of this condition (Aicale et al., 2018). The possibility of surgery should be discussed with the patient after at least 
three to 6 months of nonoperative management (Maffulli et al., 2020). Good outcomes have been obtained in refractory cases in Achilles tendinopathy with the use of surgery (Aicale et al., 2018). However, we need for further controlled studies to evaluate and improve more novel treatment approaches (Aicale et al., 2018).

Patients should understand that symptoms may recur with either conservative or surgical approaches. Teaching patients to control the symptoms may be more beneficial than leading them to believe that Achilles tendinopathy is fully curable (Maffulli et al., 2020).

\section{REFERENCES}

Aicale, R., Tarantino, D., \& Maffulli, N. (2017). Basic Science of Tendons. In A. Gobbi, J. EspregueiraMendes, J. G. Lane, \& M. Karahan, Bio-orthopaedics: A New Approach (pagg. 249-273). Springer. https://doi.org/10.1007/978-3-662-54181-4_21

Aicale, R., Tarantino, D., \& Maffulli, N. (2018). Overuse injuries in sport: A comprehensive overview. Journal of Orthopaedic Surgery and Research, 13(1), 309. https://doi.org/10.1186/s13018-018-1017$\underline{5}$

Aicale, R., Tarantino, D., Giai Via, A., Oliva, F., \& Maffulli, N. (2017). Z Shortening of Healed Achilles Tendon Rupture (pagg. 125-128). https://doi.org/10.1007/978-3-662-54074-9_21

Aicale, R., Tarantino, D., \& Maffulli, N. (2018). Surgery in Tendinopathies. Sports Medicine and Arthroscopy Review, 26(4), 200-202. https://doi.org/10.1097/JSA.0000000000000214

Aicale, R., Tarantino, D., \& Maffulli, N. (2019). Non-insertional Achilles Tendinopathy: State of the Art (pagg. 359-367). https://doi.org/10.1007/978-3-662-58704-1_32

Aicale, R., Tarantino, D., Oliva, F., Carmont, M., \& Maffulli, N. (2017a). Ipsilateral Free Semitendinosus Tendon Graft with Interference Screw Fixation (pagg. 93-97). https://doi.org/10.1007/978-3-662$\underline{54074-9 \_16}$

Aicale, R., Tarantino, D., Oliva, F., Carmont, M. R., \& Maffulli, N. (2017b). Minimally Invasive Peroneus Brevis Tendon Transfer. In Hajo Thermann, C. Becher, M. R. Carmont, J. Karlsson, N. Maffulli, \& J. Calder, The Achilles Tendon: An Atlas of Surgical Procedures (pagg. 89-92). Springer. https://doi.org/10.1007/978-3-662-54074-9_15

Alfredson, H., Pietilä, T., Jonsson, P., \& Lorentzon, R. (1998). Heavy-load eccentric calf muscle training for the treatment of chronic Achilles tendinosis. The American Journal of Sports Medicine, 26(3), 360-366. https://doi.org/10.1177/03635465980260030301

Alfredson, H. (2011a). Ultrasound and Doppler-guided mini-surgery to treat midportion Achilles tendinosis: Results of a large material and a randomised study comparing two scraping techniques. British Journal of Sports Medicine, 45(5), 407-410. https://doi.org/10.1136/bjsm.2010.081216

Alfredson, H.. (2011b). Midportion Achilles tendinosis and the plantaris tendon. British Journal of Sports Medicine, 45(13), 1023-1025. https://doi.org/10.1136/bjsports-2011-090217

Al-Mouazzen, L., Rajakulendran, K., Najefi, A., \& Ahad, N. (2015). Percutaneous repair followed by accelerated rehabilitation for acute Achilles tendon ruptures. Journal of Orthopaedic Surgery (Hong Kong), 23(3), 352-356. https://doi.org/10.1177/230949901502300320

Bertelli, R., Gaiani, L., \& Palmonari, M. (2009). Neglected rupture of the Achilles tendon treated with a percutaneous technique. Foot and Ankle Surgery: Official Journal of the European Society of Foot and Ankle Surgeons, 15(4), 169-173. https://doi.org/10.1016/j.fas.2008.12.003

Bisaccia, D. R., Aicale, R., Tarantino, D., Peretti, G. M., \& Maffulli, N. (2019). Biological and chemical changes in fluoroquinolone-associated tendinopathies: A systematic review. British Medical Bulletin, 130(1), 39-49. https://doi.org/10.1093/bmb/ldz006 
Boesen, A. P., Hansen, R., Boesen, M. I., Malliaras, P., \& Langberg, H. (2017). Effect of High-Volume Injection, Platelet-Rich Plasma, and Sham Treatment in Chronic Midportion Achilles Tendinopathy: A Randomized Double-Blinded Prospective Study. The American Journal of Sports Medicine, 45(9), 2034-2043. https://doi.org/10.1177/0363546517702862

Bostick, G. P., Jomha, N. M., Suchak, A. A., \& Beaupré, L. A. (2010). Factors associated with calf muscle endurance recovery 1 year after achilles tendon rupture repair. The Journal of Orthopaedic and Sports Physical Therapy, 40(6), 345-351. https://doi.org/10.2519/jospt.2010.3204

Calder, J. D. F., Freeman, R., \& Pollock, N. (2015). Plantaris excision in the treatment of non-insertional Achilles tendinopathy in elite athletes. British Journal of Sports Medicine, 49(23), 1532-1534. https://doi.org/10.1136/bjsports-2014-093827

Carmont, M. R., \& Maffulli, N. (2008). Modified percutaneous repair of ruptured Achilles tendon. Knee Surgery, Sports Traumatology, Arthroscopy: Official Journal of the ESSKA, 16(2), 199-203. https://doi.org/10.1007/s00167-007-0411-z

Carmont, M. R., Rossi, R., Scheffler, S., Mei-Dan, O., \& Beaufils, P. (2011). Percutaneous \& Mini Invasive Achilles tendon repair. Sports Medicine, Arthroscopy, Rehabilitation, Therapy \& Technology: SMARTT, 3, 28. https://doi.org/10.1186/1758-2555-3-28

Carmont, M. R., Silbernagel, K. G., Nilsson-Helander, K., \& Karlsson, J. (2017). Free Hamstring Open Augmentation for Delayed Achilles Tendon Rupture. In Hajo Thermann, C. Becher, M. R. Carmont, J. Karlsson, N. Maffulli, \& J. Calder, The Achilles Tendon: An Atlas of Surgical Procedures (pagg. 85-88). Springer. https://doi.org/10.1007/978-3-662-54074-9_14

Chan, O., O'Dowd, D., Padhiar, N., Morrissey, D., King, J., Jalan, R., Maffulli, N., \& Crisp, T. (2008). High volume image guided injections in chronic Achilles tendinopathy. Disability and Rehabilitation, 30(2022), 1697-1708. https://doi.org/10.1080/09638280701788225

Chester, R., Costa, M. L., Shepstone, L., Cooper, A., \& Donell, S. T. (2008). Eccentric calf muscle training compared with therapeutic ultrasound for chronic Achilles tendon pain-A pilot study. Manual Therapy, 13(6), 484-491. https://doi.org/10.1016/j.math.2007.05.014

Corrado, B., Albano, M., Caprio, M. G., Di Luise, C., Sansone, M., Servodidio, V., Russo, S., Vallone, G., Vola, E. A., \& lammarrone, C. S. (2019). Usefulness of point shear wave elastography to assess the effects of extracorporeal shockwaves on spastic muscles in children with cerebral palsy: An uncontrolled experimental study. Muscles, Ligaments \& Tendons Journal (MLTJ), 9(1), 124-130. https://doi.org/10.32098/mlti.01.2019.04

Corrado, B., Di Luise Carla, \& Servodio lammarrone Clemente. (2019). Management of Muscle Spasticity in Children with Cerebral Palsy by Means of Extracorporeal Shockwave Therapy: A Systematic Review of the Literature. 1-7-7. https://doi.org/10.1080/17518423.2019.1683908

Corrado, Bruno, Ciardi, G., Fortunato, L., \& lammarrone, C. S. (2019). Burnout syndrome among Italian physiotherapists: A cross-sectional study. European Journal of Physiotherapy, 21(4), 240-245. https://doi.org/10.1080/21679169.2018.1536765

Corrado, B, Bonini, I., Chirico, V., Filippini, E., Liguori, L., Magliulo, G., Mazzuoccolo, G., Rosano, N., \& Gisonni, P. (2020). Ultrasound-guided collagen injections in the treatment of supraspinatus tendinopathy: A case series pilot study. Journal of Biological Regulators and Homeostatic Agents, 34(3-S2), 33-39.

Corrado, B., Mazzuoccolo, G., Liguori, L., Chirico, V. A., Costanzo, M., Bonini, I., Bove, G., \& Curci, L. (2019). Treatment of Lateral Epicondylitis with Collagen Injections: A Pilot Study. Muscle Ligaments and Tendons Journal, 09(04), 584. https://doi.org/10.32098/mltj.04.2019.14

Corrado, B., Bonini, I., Tarantino, D., \& Sirico, F. (2020). Ultrasound-guided collagen injections for treatment of plantar fasciopathy in runners: A pilot study and case series. https://doi.org/10.14198/ihse.2020.15.Proc3.30 
Costa, M. L., Shepstone, L., Donell, S. T., \& Thomas, T. L. (2005). Shock wave therapy for chronic Achilles tendon pain: A randomized placebo-controlled trial. Clinical Orthopaedics and Related Research, 440, 199-204. https://doi.org/10.1097/01.blo.0000180451.03425.48

Costa, M. L., Achten, J., Wagland, S., Marian, I. R., Maredza, M., Schlüssel, M. M., Liew, A. S., Parsons, N. R., Dutton, S. J., Kearney, R. S., Lamb, S. E., Ollivere, B., \& Petrou, S. (2020). Plaster cast versus functional bracing for Achilles tendon rupture: The UKSTAR RCT. Health Technology Assessment (Winchester, England), 24(8), 1-86. https://doi.org/10.3310/hta24080

Costa, M. L., Logan, K., Heylings, D., Donell, S. T., \& Tucker, K. (2006). The effect of achilles tendon lengthening on ankle dorsiflexion: A cadaver study. Foot \& Ankle International, 27(6), 414-417. https://doi.org/10.1177/107110070602700605

d'Addona, A., Rocca, F. D., Carrella, D., Corrado, B., Sirico, F., lorio, P., \& Balato, G. (2020). Effectiveness of endoscopic trans-tendineous repair for partial-thickness tears of medius gluteus: A systematic review of literature. Journal of Human Sport and Exercise, Extra 3, 770-780. https://doi.org/10.14198/ihse.2020.15.Proc3.27

de Jonge, S., de Vos, R. J., Van Schie, H. T. M., Verhaar, J. a. N., Weir, A., \& Tol, J. L. (2010). One-year follow-up of a randomised controlled trial on added splinting to eccentric exercises in chronic midportion Achilles tendinopathy. British Journal of Sports Medicine, 44(9), 673-677. https://doi.org/10.1136/bjsm.2008.052142

de Vos, R. J., Weir, A., van Schie, H. T. M., Bierma-Zeinstra, S. M. A., Verhaar, J. A. N., Weinans, H., \& Tol, J. L. (2010). Platelet-rich plasma injection for chronic Achilles tendinopathy: A randomized controlled trial. JAMA, 303(2), 144-149. https://doi.org/10.1001/jama.2009.1986

Deng, S., Sun, Z., Zhang, C., Chen, G., \& Li, J. (2017). Surgical Treatment Versus Conservative Management for Acute Achilles Tendon Rupture: A Systematic Review and Meta-Analysis of Randomized Controlled Trials. The Journal of Foot and Ankle Surgery: Official Publication of the American College of Foot and Ankle Surgeons, 56(6), 1236-1243. https://doi.org/10.1053/i.jfas.2017.05.036

Di Meglio, F., Sacco, A. M., Belviso, I., Romano, V., Camargo, F., Loiacono, C., Palermi, S., Pempinello, C., Montagnani, S., Nurzynska, D., \& Castaldo, C. (2020). Influence of Supplements and Drugs used for the Treatment of Musculoskeletal Disorders on Adult Human Tendon-Derived Stem Cells. Muscle Ligaments and Tendons Journal, 10(03), 376. https://doi.org/10.32098/mlti.03.2020.04

Eames, M. H., Eames, N. W., McCarthy, K. R., \& Wallace, R. G. (1997). An audit of the combined nonoperative and orthotic management of ruptured tendo Achillis. Injury, 28(4), 289-292. https://doi.org/10.1016/S0020-1383(96)00203-3

Ecker, T. M., Bremer, A. K., Krause, F. G., Müller, T., \& Weber, M. (2016). Prospective Use of a Standardized Nonoperative Early Weightbearing Protocol for Achilles Tendon Rupture: 17 Years of Experience. The American Journal of Sports Medicine, 44(4), 1004-1010. https://doi.org/10.1177/0363546515623501

Edna, T. H. (1980). Non-operative treatment of Achilles tendon ruptures. Acta Orthopaedica Scandinavica, 51(6), 991-993. https://doi.org/10.3109/17453678008990905

Farizon, F., Pages, A., Azoulai, J. J., de Lavison, R., \& Bousquet, G. (1997). [Surgical treatment of ruptures of the Achilles tendon. Apropos of 42 cases treated by Bosworth's technique]. Revue De Chirurgie Orthopedique Et Reparatrice De L'appareil Moteur, 83(1), 65-69.

Gillies, H., \& Chalmers, J. (1970). The management of fresh ruptures of the tendo achillis. The Journal of Bone and Joint Surgery. American Volume, 52(2), 337-343. https://doi.org/10.2106/00004623$\underline{197052020-00015}$ 
Giombini, A., Di Cesare, A., Casciello, G., Sorrenti, D., Dragoni, S., \& Gabriele, P. (2002). Hyperthermia at $434 \mathrm{MHz}$ in the treatment of overuse sport tendinopathies: A randomised controlled clinical trial. International Journal of Sports Medicine, 23(3), 207-211. https://doi.org/10.1055/s-2002-23180

Glaser, T., Poddar, S., Tweed, B., \& Webb, C. W. (2008). Clinical inquiries. What's the best way to treat Achilles tendonopathy? The Journal of Family Practice, 57(4), 261-263.

Goren, D., Ayalon, M., \& Nyska, M. (2005). Isokinetic strength and endurance after percutaneous and open surgical repair of Achilles tendon ruptures. Foot \& Ankle International, 26(4), 286-290. https://doi.org/10.1177/107110070502600404

Gross, C. E., \& Nunley, J. A. (2016). Acute Achilles Tendon Ruptures. Foot \& Ankle International, 37(2), 233-239. https://doi.org/10.1177/1071100715619606

Guillo, S., Del Buono, A., Dias, M., Denaro, V., \& Maffulli, N. (2013). Percutaneous repair of acute ruptures of the tendo Achillis. The Surgeon: Journal of the Royal Colleges of Surgeons of Edinburgh and Ireland, 11(1), 14-19. https://doi.org/10.1016/.surge.2011.12.002

Häggmark, T., Liedberg, H., Eriksson, E., \& Wredmark, T. (1986). Calf muscle atrophy and muscle function after non-operative vs operative treatment of achilles tendon ruptures. Orthopedics, 9(2), 160-164.

Heikkinen, J., Lantto, I., Flinkkila, T., Ohtonen, P., Niinimaki, J., Siira, P., Laine, V., \& Leppilahti, J. (2017). Soleus Atrophy Is Common After the Nonsurgical Treatment of Acute Achilles Tendon Ruptures: A Randomized Clinical Trial Comparing Surgical and Nonsurgical Functional Treatments. The American Journal of Sports Medicine, 45(6), 1395-1404. https://doi.org/10.1177/0363546517694610

Heikkinen, J., Lantto, I., Flinkkilä, T., Ohtonen, P., Pajala, A., Siira, P., \& Leppilahti, J. (2016). Augmented Compared with Nonaugmented Surgical Repair After Total Achilles Rupture: Results of a Prospective Randomized Trial with Thirteen or More Years of Follow-up. The Journal of Bone and Joint Surgery. American Volume, 98(2), 85-92. https://doi.org/10.2106/JBJS.0.00496

Horstmann, T., Lukas, C., Merk, J., Brauner, T., \& Mündermann, A. (2012). Deficits 10-years after Achilles tendon repair. International Journal of Sports Medicine, 33(6), 474-479. https://doi.org/10.1055/s-0032-1301932

Hsu, A. R., Cohen, B. E., \& Anderson, R. B. (2017). Open Reconstruction with Gastrocnemius V-Y Advancement. In H. Thermann, C. Becher, M. R. Carmont, J. Karlsson, N. Maffulli, \& J. Calder, The Achilles Tendon: An Atlas of Surgical Procedures (pagg. 75-80). Springer.

Jacobs, D., Martens, M., Van Audekercke, R., Mulier, J. C., \& Mulier, F. (1978). Comparison of conservative and operative treatment of Achilles tendon rupture. The American Journal of Sports Medicine, 6(3), 107-111. https://doi.org/10.1177/036354657800600302

Kader, D., Saxena, A., Movin, T., \& Maffulli, N. (2002). Achilles tendinopathy: Some aspects of basic science and clinical management. British Journal of Sports Medicine, 36(4), 239-249. https://doi.org/10.1136/bjsm.36.4.239

Kane, T. P. C., Ismail, M., \& Calder, J. D. F. (2008). Topical glyceryl trinitrate and noninsertional Achilles tendinopathy: A clinical and cellular investigation. The American Journal of Sports Medicine, 36(6), 1160-1163. https://doi.org/10.1177/0363546508314423

Kannus, P., \& Józsa, L. (1991). Histopathological changes preceding spontaneous rupture of a tendon. A controlled study of 891 patients. The Journal of Bone and Joint Surgery. American Volume, 73(10), 1507-1525. https://doi.org/10.2106/00004623-199173100-00009

Karabinas, P. K., Benetos, I. S., Lampropoulou-Adamidou, K., Romoudis, P., Mavrogenis, A. F., \& Vlamis, J. (2014). Percutaneous versus open repair of acute Achilles tendon ruptures. European Journal of Orthopaedic Surgery \& Traumatology: Orthopedie Traumatologie, 24(4), 607-613. https://doi.org/10.1007/s00590-013-1350-7 
Karlsson, J., Olsson, N., Carmont, M. R., \& Nilsson-Helander, K. (2017). Open Standard Technique. In Hajo Thermann, M. R. Carmont, N. Maffulli, \& van D. C. Niek, The Achilles Tendon: An Atlas of Surgical Procedures (pagg. 3-6). Springer. https://doi.org/10.1007/978-3-662-54074-9_1

Khan, R. J. K., Fick, D., Brammar, T. J., Crawford, J., \& Parker, M. J. (2004). Interventions for treating acute Achilles tendon ruptures. The Cochrane Database of Systematic Reviews, 3, CD003674. https://doi.org/10.1002/14651858.CD003674.pub2

Khan, R. J. K., Fick, D., Keogh, A., Crawford, J., Brammar, T., \& Parker, M. (2005). Treatment of acute achilles tendon ruptures. A meta-analysis of randomized, controlled trials. The Journal of Bone and Joint Surgery. American Volume, 87(10), 2202-2210. https://doi.org/10.2106/JBJS.D.03049

Knobe, M., Gradl, G., Klos, K., Corsten, J., Dienstknecht, T., Rath, B., Sönmez, T. T., Hoeckle, C., \& Pape, H.-C. (2015). Is percutaneous suturing superior to open fibrin gluing in acute Achilles tendon rupture? International Orthopaedics, 39(3), 535-542. https://doi.org/10.1007/s00264-014-2615-4

Knobloch, K., Schreibmueller, L., Longo, U. G., \& Vogt, P. M. (2008a). Eccentric exercises for the management of tendinopathy of the main body of the Achilles tendon with or without an AirHeel Brace. A randomized controlled trial. B: Effects of compliance. Disability and Rehabilitation, 30(2022), 1692-1696. https://doi.org/10.1080/09638280701785676

Knobloch, K., Schreibmueller, L., Longo, U. G., \& Vogt, P. M. (2008b). Eccentric exercises for the management of tendinopathy of the main body of the Achilles tendon with or without the AirHeel Brace. A randomized controlled trial. A: Effects on pain and microcirculation. Disability and Rehabilitation, 30(20-22), 1685-1691. https://doi.org/10.1080/09638280701786658

Korkmaz, M., Erkoc, M. F., Yolcu, S., Balbaloglu, O., Öztemur, Z., \& Karaaslan, F. (2015). Weight bearing the same day versus non-weight bearing for 4 weeks in Achilles tendon rupture. Journal of Orthopaedic Science: Official Journal of the Japanese Orthopaedic Association, 20(3), 513-516. https://doi.org/10.1007/s00776-015-0710-z

Kvist, H., \& Kvist, M. (1980). The operative treatment of chronic calcaneal paratenonitis. The Journal of Bone and Joint Surgery. British Volume, 62(3), 353-357. https://doi.org/10.1302/0301620X.62B3.7410468

Lantto, I., Heikkinen, J., Flinkkilä, T., Ohtonen, P., \& Leppilahti, J. (2015). Epidemiology of Achilles tendon ruptures: Increasing incidence over a 33-year period. Scandinavian Journal of Medicine \& Science in Sports, 25(1), e133-138. https://doi.org/10.1111/sms.12253

Lantto, I., Heikkinen, J., Flinkkila, T., Ohtonen, P., Kangas, J., Siira, P., \& Leppilahti, J. (2015). Early functional treatment versus cast immobilization in tension after achilles rupture repair: Results of a prospective randomized trial with 10 or more years of follow-up. The American Journal of Sports Medicine, 43(9), 2302-2309. https://doi.org/10.1177/0363546515591267

Lea, R. B., \& Smith, L. (1972). Non-surgical treatment of tendo achillis rupture. The Journal of Bone and Joint Surgery. American Volume, 54(7), 1398-1407. https://doi.org/10.2106/00004623-19725407000002

Lildholdt, T., \& Munch-Jorgensen, T. (1976). Conservative treatment to Achilles tendon rupture. A followup study of 14 cases. Acta Orthopaedica Scandinavica, 47(4), 454-458. https://doi.org/10.3109/17453677608988719

Lin, T. W. T. W., Cardenas, L., \& Soslowsky, L. J. L. J. (2004). Biomechanics of tendon injury and repair. Journal of Biomechanics, 37(6), 865-877. https://doi.org/10.1016/j.jbiomech.2003.11.005

Lohrer, H., David, S., \& Nauck, T. (2016). Surgical treatment for achilles tendinopathy-A systematic review. BMC Musculoskeletal Disorders, 17, 207. https://doi.org/10.1186/s12891-016-1061-4

Loiacono, C., Palermi, S., Massa, B., Belviso, I., Romano, V., Di Gregorio, A., Sirico, F., \& Sacco, A. M. (2019). Tendinopathy: Pathophysiology, Therapeutic Options, and Role of Nutraceutics. A Narrative Literature Review. Medicina, 55(8). https://doi.org/10.3390/medicina55080447 
Longo, U. G., Petrillo, S., Maffulli, N., \& Denaro, V. (2013). Acute achilles tendon rupture in athletes. Foot and Ankle Clinics, 18(2), 319-338. https://doi.org/10.1016/.ffl.2013.02.009

Longo, U. G., Ramamurthy, C., Denaro, V., \& Maffulli, N. (2008). Minimally invasive stripping for chronic Achilles tendinopathy. Disability and Rehabilitation, 30(20-22), 1709-1713. https://doi.org/10.1080/09638280701786922

Longo, U. G., Ronga, M., \& Maffulli, N. (2009). Achilles tendinopathy. Sports Medicine and Arthroscopy Review, 17(2), 112-126. https://doi.org/10.1097/JSA.0b013e3181a3d625

Lowdon, A., Bader, D. L., \& Mowat, A. G. (1984). The effect of heel pads on the treatment of Achilles tendinitis: A double blind trial. The American Journal of Sports Medicine, 12(6), 431-435. https://doi.org/10.1177/036354658401200605

Ma, G. W., \& Griffith, T. G. (1977). Percutaneous repair of acute closed ruptured achilles tendon: A new technique. Clinical Orthopaedics and Related Research, 128, 247-255. https://doi.org/10.1097/00003086-197710000-00036

Maes, R., Copin, G., \& Averous, C. (2006). Is percutaneous repair of the Achilles tendon a safe technique? A study of 124 cases. Acta orthopaedica Belgica, 72, 179-183.

Maffulli, G., Buono, A. D., Richards, P., Oliva, F., \& Maffulli, N. (2017). Conservative, minimally invasive and open surgical repair for management of acute ruptures of the Achilles tendon: A clinical and functional retrospective study. Muscles, Ligaments and Tendons Journal, 7(1), 46-52. https://doi.org/10.11138/mltj/2017.7.1.046

Maffulli, N., Binfield, P. M., Moore, D., \& King, J. B. (1999). Surgical decompression of chronic central core lesions of the Achilles tendon. The American Journal of Sports Medicine, 27(6), 747-752. https://doi.org/10.1177/03635465990270061101

Maffulli, N., Khan, K. M., \& Puddu, G. (1998). Overuse tendon conditions: Time to change a confusing terminology. Arthroscopy: The Journal of Arthroscopic \& Related Surgery: Official Publication of the Arthroscopy Association of North America and the International Arthroscopy Association, 14(8), 840 843. https://doi.org/10.1016/s0749-8063(98)70021-0

Maffulli, N., \& Longo, U. G. (2008a). Conservative management for tendinopathy: Is there enough scientific evidence? Rheumatology (Oxford, England), 47(4), 390-391. https://doi.org/10.1093/rheumatology/ken011

Maffulli, N., \& Longo, U. G. (2008b). How do eccentric exercises work in tendinopathy? Rheumatology (Oxford, England), 47(10), 1444-1445. https://doi.org/10.1093/rheumatology/ken337

Maffulli, N., Tallon, C., Wong, J., Peng Lim, K., \& Bleakney, R. (2003). No adverse effect of early weight bearing following open repair of acute tears of the Achilles tendon. The Journal of Sports Medicine and Physical Fitness, 43(3), 367-379.

Maffulli, N., Testa, V., Capasso, G., Bifulco, G., \& Binfield, P. M. (1997). Results of percutaneous longitudinal tenotomy for Achilles tendinopathy in middle- and long-distance runners. The American Journal of Sports Medicine, 25(6), 835-840. https://doi.org/10.1177/036354659702500618

Maffulli, N., Waterston, S. W., Squair, J., Reaper, J., \& Douglas, A. S. (1999). Changing incidence of Achilles tendon rupture in Scotland: A 15-year study. Clinical Journal of Sport Medicine: Official Journal of the Canadian Academy of Sport Medicine, 9(3), 157-160. https://doi.org/10.1097/00042752-199907000-00007

Maffulli, Nicola. (2006). Immediate weight-bearing is not detrimental to operatively or conservatively managed rupture of the Achilles tendon. The Australian Journal of Physiotherapy, 52(3), 225. https://doi.org/10.1016/S0004-9514(06)70033-2

Maffulli, N., Aicale, R., \& Tarantino, D. (2017a). Autograft Reconstruction for Chronic Achilles Tendon Disorders. Techniques in Foot \& Ankle Surgery, 16(3), 117-123. https://doi.org/10.1097/BTF.0000000000000154 
Maffulli, N., Aicale, R., \& Tarantino, D. (2020). Tendinopathy of the Achilles Tendon (pagg. 227-237). https://doi.org/10.1007/978-3-030-29231-7_31

Maffulli, N., Aicale, R., Tarantino, D., Moretti, L., \& Moretti, B. (2018). Lesioni da sovraccarico.

Maffulli, N., \& Kader, D. (2002). Tendinopathy of tendo achillis. The Journal of Bone and Joint Surgery. British Volume, 84(1), 1-8. https://doi.org/10.1302/0301-620x.84b1.12792

Maffulli, N., Longo, U. G., Kadakia, A., \& Spiezia, F. (2020). Achilles tendinopathy. Foot and Ankle Surgery: Official Journal of the European Society of Foot and Ankle Surgeons, 26(3), 240-249. https://doi.org/10.1016/j.fas.2019.03.009

Maffulli, N., Longo, U. G., Maffulli, G. D., Khanna, A., \& Denaro, V. (2011a). Achilles tendon ruptures in diabetic patients. Archives of Orthopaedic and Trauma Surgery, 131(1), 33-38. https://doi.org/10.1007/s00402-010-1097-0

Maffulli, N., Longo, U. G., Maffulli, G. D., Khanna, A., \& Denaro, V. (2011b). Achilles tendon ruptures in elite athletes. Foot \& Ankle International, 32(1), 9-15. https://doi.org/10.3113/FAl.2011.0009

Maffulli, N., Longo, U. G., Ronga, M., Khanna, A., \& Denaro, V. (2010). Favorable outcome of percutaneous repair of achilles tendon ruptures in the elderly. Clinical Orthopaedics and Related Research, 468(4), 1039-1046. https://doi.org/10.1007/s11999-009-0944-1

Maffulli, N., Longo, U. G., Spiezia, F., \& Denaro, V. (2010). Minimally invasive surgery for Achilles tendon pathologies. Open Access Journal of Sports Medicine, 1, 95-103. https://doi.org/10.2147/OAJSM.S7752

Maffulli, N., Oliva, F., Maffulli, G. D., Giai Via, A., \& Gougoulias, N. (2017). Minimally Invasive Achilles Tendon Stripping for the Management of Tendinopathy of the Main Body of the Achilles Tendon. The Journal of Foot and Ankle Surgery: Official Publication of the American College of Foot and Ankle Surgeons, 56(5), 938-942. https://doi.org/10.1053/.jfas.2017.05.019

Maffulli, N., \& Peretti, G. M. (2019). Surgery or conservative management for Achilles tendon rupture? BMJ (Clinical Research Ed.), 364, k5344. https://doi.org/10.1136/bmj.k5344

Maffulli, N., \& Peretti, G. M. (2020). Treatment decisions for acute Achilles tendon ruptures. Lancet (London, England), 395(10222), 397-398. https://doi.org/10.1016/S0140-6736(19)33133-2

Maffulli, N., Tallon, C., Wong, J., Lim, K. P., \& Bleakney, R. (2003). Early weightbearing and ankle mobilization after open repair of acute midsubstance tears of the achilles tendon. The American Journal of Sports Medicine, 31(5), 692-700. https://doi.org/10.1177/03635465030310051001

Maffulli, N., Via, A. G., \& Oliva, F. (2015). Chronic Achilles Tendon Disorders: Tendinopathy and Chronic Rupture. Clinics in Sports Medicine, 34(4), 607-624. https://doi.org/10.1016/j.csm.2015.06.010

Mafi, N., Lorentzon, R., \& Alfredson, H. (2001). Superior short-term results with eccentric calf muscle training compared to concentric training in a randomized prospective multicenter study on patients with chronic Achilles tendinosis. Knee Surgery, Sports Traumatology, Arthroscopy: Official Journal of the ESSKA, 9(1), 42-47. https://doi.org/10.1007/s001670000148

Majewski, M., Rohrbach, M., Czaja, S., \& Ochsner, P. (2006). Avoiding sural nerve injuries during percutaneous Achilles tendon repair. The American Journal of Sports Medicine, 34(5), 793-798. https://doi.org/10.1177/0363546505283266

Malliaras, P., Barton, C. J., Reeves, N. D., \& Langberg, H. (2013). Achilles and patellar tendinopathy loading programmes: A systematic review comparing clinical outcomes and identifying potential mechanisms for effectiveness. Sports Medicine (Auckland, N.Z.), 43(4), 267-286. https://doi.org/10.1007/s40279-013-0019-z

Manent, A., López, L., Corominas, H., Santamaría, A., Domínguez, A., Llorens, N., Sales, M., \& Videla, S. (2019). Acute Achilles Tendon Ruptures: Efficacy of Conservative and Surgical (Percutaneous, Open) Treatment-A Randomized, Controlled, Clinical Trial. The Journal of Foot and Ankle Surgery: 
Official Publication of the American College of Foot and Ankle Surgeons, 58(6), 1229-1234. https://doi.org/10.1053/j.jas.2019.02.002

Maquirriain, J. (2011). Achilles Tendon Rupture: Avoiding Tendon Lengthening during Surgical Repair and Rehabilitation. The Yale Journal of Biology and Medicine, 84(3), 289-300.

Masci, L., Spang, C., Schie, H. T. M. van, \& Alfredson, H. (2015). Achilles tendinopathy-do plantaris tendon removal and Achilles tendon scraping improve tendon structure? A prospective study using ultrasound tissue characterisation. BMJ Open Sport \& Exercise Medicine, 1(1), e000005. https://doi.org/10.1136/bmjsem-2015-000005

Mavrodontidis, A., Lykissas, M., Koulouvaris, P., Pafilas, D., Kontogeorgakos, V., \& Zalavras, C. (2015). Percutaneous repair of acute Achilles tendon rupture: A functional evaluation study with a minimum 10-year follow-up. Acta Orthopaedica Et Traumatologica Turcica, 49(6), 661-667.

McClelland, D., \& Maffulli, N. (2002). Percutaneous repair of ruptured Achilles tendon. Journal of the Royal College of Surgeons of Edinburgh, 47(4), 613-618.

McComis, G. P., Nawoczenski, D. A., \& DeHaven, K. E. (1997). Functional bracing for rupture of the Achilles tendon. Clinical results and analysis of ground-reaction forces and temporal data. The Journal of Bone and Joint Surgery. American Volume, 79(12), 1799-1808. https://doi.org/10.2106/00004623-199712000-00005

Metz, R., Verleisdonk, E.-J. M. M., van der Heijden, G. J.-M.-G., Clevers, G.-J., Hammacher, E. R., Verhofstad, M. H. J., \& van der Werken, C. (2008). Acute Achilles tendon rupture: Minimally invasive surgery versus nonoperative treatment with immediate full weightbearing--a randomized controlled trial. The American Journal of Sports Medicine, 36(9), 1688-1694. https://doi.org/10.1177/0363546508319312

Metz, R., van der Heijden, G. J. M. G., Verleisdonk, E.-J. M. M., Tamminga, R., \& van der Werken, C. (2009). Recovery of calf muscle strength following acute achilles tendon rupture treatment: A comparison between minimally invasive surgery and conservative treatment. Foot \& Ankle Specialist, 2(5), 219-226. https://doi.org/10.1177/1938640009348338

Möller, M., Movin, T., Granhed, H., Lind, K., Faxén, E., \& Karlsson, J. (2001). Acute rupture of tendon Achillis. A prospective randomised study of comparison between surgical and non-surgical treatment. The Journal of Bone and Joint Surgery. British Volume, 83(6), 843-848. https://doi.org/10.1302/0301620X.83B6.0830843

Myerson, M. S. (1999). Achilles tendon ruptures. Instructional Course Lectures, 48, 219-230.

Niesen-Vertommen, S. L., Taunton, J. E., Clement, D. B., \& Mosher, R. E. (1992). The effect of eccentric versus concentric exercise in the management of Achilles tendonitis. Clinical Journal of Sport Medicine, 2(2), 109-113. https://doi.org/10.1097/00042752-199204000-00006

Nilsson-Helander, K., Swärd, L., Carmont, M. R., Olsson, N., \& Karlsson, J. (2017). Free/Turndown Gastrocnemius Flap Augmentation. In Hajo Thermann, C. Becher, M. R. Carmont, J. Karlsson, N. Maffulli, \& J. Calder, The Achilles Tendon: An Atlas of Surgical Procedures (pagg. 81-84). Springer. https://doi.org/10.1007/978-3-662-54074-9 13

Ochen, Y., Beks, R. B., Heijl, M. van, Hietbrink, F., Leenen, L. P. H., Velde, D. van der, Heng, M., Meijden, O. van der, Groenwold, R. H. H., \& Houwert, R. M. (2019). Operative treatment versus nonoperative treatment of Achilles tendon ruptures: Systematic review and meta-analysis. BMJ, 364. https://doi.org/10.1136/bmi.k5120

Oda, H., Sano, K., Kunimasa, Y., Komi, P. V., \& Ishikawa, M. (2017). Neuromechanical Modulation of the Achilles Tendon During Bilateral Hopping in Patients with Unilateral Achilles Tendon Rupture, Over 1 Year After Surgical Repair. Sports Medicine (Auckland, N.Z.), 47(6), 1221-1230. https://doi.org/10.1007/s40279-016-0629-3 
Okoroha, K. R., Ussef, N., Jildeh, T. R., Khalil, L. S., Hasan, L., Bench, C., Zeni, F., Eller, E., \& Moutzouros, V. (2020). Comparison of Tendon Lengthening With Traditional Versus Accelerated Rehabilitation After Achilles Tendon Repair: A Prospective Randomized Controlled Trial. The American Journal of Sports Medicine, 48(7), 1720-1726. https://doi.org/10.1177/0363546520909389

Olsson, N., Nilsson-Helander, K., Karlsson, J., Eriksson, B. I., Thomée, R., Faxén, E., \& Silbernagel, K. G. (2011). Major functional deficits persist 2 years after acute Achilles tendon rupture. Knee Surgery, Sports Traumatology, Arthroscopy: Official Journal of the ESSKA, 19(8), 1385-1393. https://doi.org/10.1007/s00167-011-1511-3

Olsson, N., Silbernagel, K. G., Eriksson, B. I., Sansone, M., Brorsson, A., Nilsson-Helander, K., \& Karlsson, J. (2013). Stable surgical repair with accelerated rehabilitation versus nonsurgical treatment for acute Achilles tendon ruptures: A randomized controlled study. The American Journal of Sports Medicine, 41(12), 2867-2876. https://doi.org/10.1177/0363546513503282

Paavola, M., Orava, S., Leppilahti, J., Kannus, P., \& Järvinen, M. (2000). Chronic Achilles tendon overuse injury: Complications after surgical treatment. An analysis of 432 consecutive patients. The American Journal of Sports Medicine, 28(1), 77-82. https://doi.org/10.1177/03635465000280012501

Paoloni, Justin A., Appleyard, R. C., Nelson, J., \& Murrell, G. A. C. (2004). Topical glyceryl trinitrate treatment of chronic noninsertional achilles tendinopathy. A randomized, double-blind, placebocontrolled trial. The Journal of Bone and Joint Surgery. American Volume, 86(5), 916-922. https://doi.org/10.2106/00004623-200405000-00005

Paoloni, Justin Alan, \& Murrell, G. A. C. (2007). Three-year followup study of topical glyceryl trinitrate treatment of chronic noninsertional Achilles tendinopathy. Foot \& Ankle International, 28(10), 10641068. https://doi.org/10.3113/FAl.2007.1064

Pearce, C. J., Carmichael, J., \& Calder, J. D. (2012). Achilles tendinoscopy and plantaris tendon release and division in the treatment of non-insertional Achilles tendinopathy. Foot and Ankle Surgery: Official Journal of the European Society of Foot and Ankle Surgeons, 18(2), 124-127. https://doi.org/10.1016/j.fas.2011.04.008

Persson, A., \& Wredmark, T. (1979). The treatment of total ruptures of the Achilles tendon by plaster immobilisation. International Orthopaedics, 3(2), 149-152.

Petersen, W., Welp, R., \& Rosenbaum, D. (2007). Chronic Achilles tendinopathy: A prospective randomized study comparing the therapeutic effect of eccentric training, the AirHeel brace, and a combination of both. The American Journal of Sports Medicine, 35(10), 1659-1667. https://doi.org/10.1177/0363546507303558

Rompe, J. D., Furia, J., \& Maffulli, N. (2009). Eccentric loading versus eccentric loading plus shock-wave treatment for midportion achilles tendinopathy: A randomized controlled trial. The American Journal of Sports Medicine, 37(3), 463-470. https://doi.org/10.1177/0363546508326983

Rompe, J. D., Nafe, B., Furia, J. P., \& Maffulli, N. (2007). Eccentric loading, shock-wave treatment, or a wait-and-see policy for tendinopathy of the main body of tendo Achillis: A randomized controlled trial. The American Journal of Sports Medicine, 35(3), 374-383. https://doi.org/10.1177/0363546506295940

Roos, E. M., Engström, M., Lagerquist, A., \& Söderberg, B. (2004). Clinical improvement after 6 weeks of eccentric exercise in patients with mid-portion Achilles tendinopathy-A randomized trial with 1-year follow-up. Scandinavian Journal of Medicine \& Science in Sports, 14(5), 286-295. https://doi.org/10.1111/j.1600-0838.2004.378.x

Saleh, M., Marshall, P. D., Senior, R., \& MacFarlane, A. (1992). The Sheffield splint for controlled early mobilisation after rupture of the calcaneal tendon. A prospective, randomised comparison with plaster treatment. The Journal of Bone and Joint Surgery. British Volume, 74(2), 206-209. https://doi.org/10.1302/0301-620X.74B2.1544953 
Saxena, A., Maffulli, N., Nguyen, A., \& Li, A. (2008). Wound complications from surgeries pertaining to the Achilles tendon: An analysis of 219 surgeries. Journal of the American Podiatric Medical Association, 98(2), 95-101. https://doi.org/10.7547/0980095

Sayana, M. K., \& Maffulli, N. (2007). Eccentric calf muscle training in non-athletic patients with Achilles tendinopathy. Journal of Science and Medicine in Sport, 10(1), 52-58. https://doi.org/10.1016/j.jsams.2006.05.008

Schepsis, A. A., \& Leach, R. E. (1987). Surgical management of Achilles tendinitis. The American Journal of Sports Medicine, 15(4), 308-315. https://doi.org/10.1177/036354658701500403

Schepull, T., Kvist, J., \& Aspenberg, P. (2012). Early E-modulus of healing Achilles tendons correlates with late function: Similar results with or without surgery. Scandinavian Journal of Medicine \& Science in Sports, 22(1), 18-23. https://doi.org/10.1111/j.1600-0838.2010.01154.X

Silbernagel, K. G., Thomeé, R., Thomeé, P., \& Karlsson, J. (2001). Eccentric overload training for patients with chronic Achilles tendon pain-A randomised controlled study with reliability testing of the evaluation methods. Scandinavian Journal of Medicine \& Science in Sports, 11(4), 197-206. https://doi.org/10.1034/j.1600-0838.2001.110402.x

Silbernagel, K. G., Brorsson, A., \& Lundberg, M. (2011). The majority of patients with Achilles tendinopathy recover fully when treated with exercise alone: A 5-year follow-up. The American Journal of Sports Medicine, 39(3), 607-613. https://doi.org/10.1177/0363546510384789

Silbernagel, K. G., Nilsson-Helander, K., Thomeé, R., Eriksson, B. I., \& Karlsson, J. (2010). A new measurement of heel-rise endurance with the ability to detect functional deficits in patients with Achilles tendon rupture. Knee Surgery, Sports Traumatology, Arthroscopy: Official Journal of the ESSKA, 18(2), 258-264. https://doi.org/10.1007/s00167-009-0889-7

Silbernagel, K. G., Steele, R., \& Manal, K. (2012). Deficits in heel-rise height and achilles tendon elongation occur in patients recovering from an Achilles tendon rupture. The American Journal of Sports Medicine, 40(7), 1564-1571. https://doi.org/10.1177/0363546512447926

Sirico, F., Palermi, S., Massa, B., \& Corrado, B. (2020). Tendinopathies of the hip and pelvis in athletes: A narrative review. Journal of Human Sport and Exercise, Extra 3, 748-762. https://doi.org/10.14198/jhse.2020.15.Proc3.25

Snook, G. A. (1972). Achilles tendon tenosynovitis in long-distance runners. Medicine and Science in Sports, 4(3), 155-158. https://doi.org/10.1249/00005768-197200430-00009

Soma, C. A., \& Mandelbaum, B. R. (1995). Repair of acute Achilles tendon ruptures. The Orthopedic Clinics of North America, 26(2), 239-247.

Soroceanu, A., Sidhwa, F., Aarabi, S., Kaufman, A., \& Glazebrook, M. (2012). Surgical versus nonsurgical treatment of acute Achilles tendon rupture: A meta-analysis of randomized trials. The Journal of Bone and Joint Surgery. American Volume, 94(23), 2136-2143. https://doi.org/10.2106/JBJS.K.00917

Stanish, W. D., Rubinovich, R. M., \& Curwin, S. (1986). Eccentric exercise in chronic tendinitis. Clinical Orthopaedics and Related Research, 208, 65-68. https://doi.org/10.1097/00003086-19860700000014

Sussmilch-Leitch, S. P., Collins, N. J., Bialocerkowski, A. E., Warden, S. J., \& Crossley, K. M. (2012). Physical therapies for Achilles tendinopathy: Systematic review and meta-analysis. Journal of Foot and Ankle Research, 5(1), 15. https://doi.org/10.1186/1757-1146-5-15

Suydam, S. M., Buchanan, T. S., Manal, K., \& Silbernagel, K. G. (2015). Compensatory muscle activation caused by tendon lengthening post-Achilles tendon rupture. Knee Surgery, Sports Traumatology, Arthroscopy: Official Journal of the ESSKA, 23(3), 868-874. https://doi.org/10.1007/s00167-013$\underline{2512-1}$ 
Tarantino, D., \& Brancaccio, P. (2019, dicembre 30). Sports Injury Prevention: A Concise Review. Pharmacologyonline, 1-11.

Testa, V., Capasso, G., Benazzo, F., \& Maffulli, N. (2002). Management of Achilles tendinopathy by ultrasound-guided percutaneous tenotomy. Medicine and Science in Sports and Exercise, 34(4), 573-580. https://doi.org/10.1097/00005768-200204000-00002

Thermann, H., Hüfner, T., \& Tscherne, H. (2000). [Achilles tendon rupture]. Der Orthopade, 29(3), 235250. https://doi.org/10.1007/PL00003724

van der Eng, D. M., Schepers, T., Goslings, J. C., \& Schep, N. W. L. (2013). Rerupture rate after early weightbearing in operative versus conservative treatment of Achilles tendon ruptures: A metaanalysis. The Journal of Foot and Ankle Surgery: Official Publication of the American College of Foot and Ankle Surgeons, 52(5), 622-628. https://doi.org/10.1053/i.jfas.2013.03.027

van Sterkenburg, M. N., \& van Dijk, C. N. (2011). Injection treatment for chronic midportion Achilles tendinopathy: Do we need that many alternatives? Knee Surgery, Sports Traumatology, Arthroscopy: Official Journal of the ESSKA, 19(4), 513-515. https://doi.org/10.1007/s00167-011-1415-2

van Sterkenburg, M. N., Kerkhoffs, G. M. M. J., Kleipool, R. P., \& Niek van Dijk, C. (2011). The plantaris tendon and a potential role in mid-portion Achilles tendinopathy: An observational anatomical study. Journal of Anatomy, 218(3), 336-341. https://doi.org/10.1111/j.1469-7580.2011.01335.x

Vrbova, G. (1963). Changes in the motor reflexes produced by tenotomy. The Journal of Physiology, 166, 241-250. https://doi.org/10.1113/jphysiol.1963.sp007103

Warden, S. J. (2003). A new direction for ultrasound therapy in sports medicine. Sports Medicine (Auckland, N.Z.), 33(2), 95-107. https://doi.org/10.2165/00007256-200333020-00002

Webb, J. M., \& Bannister, G. C. (1999). Percutaneous repair of the ruptured tendo Achillis. The Journal of Bone and Joint Surgery. British Volume, 81(5), 877-880. https://doi.org/10.1302/0301620X.81B5.0810877

Weinreb, J. H., Sheth, C., Apostolakos, J., McCarthy, M.-B., Barden, B., Cote, M. P., \& Mazzocca, A. D. (2014). Tendon structure, disease, and imaging. Muscles, Ligaments and Tendons Journal, 4(1), 6673. https://doi.org/10.32098/mlti.01.2014.12

Wertz, J., Galli, M., \& Borchers, J. R. (2013). Achilles tendon rupture: Risk assessment for aerial and ground athletes. Sports Health, 5(5), 407-409. https://doi.org/10.1177/1941738112472165

Willits, K., Amendola, A., Bryant, D., Mohtadi, N. G., Giffin, J. R., Fowler, P., Kean, C. O., \& Kirkley, A. (2010). Operative versus nonoperative treatment of acute Achilles tendon ruptures: A multicenter randomized trial using accelerated functional rehabilitation. The Journal of Bone and Joint Surgery. American Volume, 92(17), 2767-2775. https://doi.org/10.2106/JBJS.I.01401

Wong, J., Barrass, V., \& Maffulli, N. (2002). Quantitative review of operative and nonoperative management of achilles tendon ruptures. The American Journal of Sports Medicine, 30(4), 565-575. https://doi.org/10.1177/03635465020300041701

Zellers, J. A., Carmont, M. R., \& Grävare Silbernagel, K. (2016). Return to play post-Achilles tendon rupture: A systematic review and meta-analysis of rate and measures of return to play. British Journal of Sports Medicine. https://doi.org/10.1136/bjsports-2016-096106

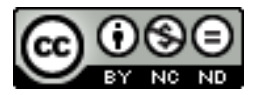

This work is licensed under a Attribution-NonCommercial-NoDerivatives 4.0 International (CC BY-NC-ND 4.0). 